\title{
Constructivismo y tecnologías en educación. Entre la innovación y el aprender a aprender
}

Artículo de investigación - Revisión https://doi.org/ 10.19053/01227238.12854

Historia del artículo:

Recibido: 31/07/2020

Evaluado: 24/01/2021

Aprobado: 20/01/2021

\section{Cómo citar este artículo:}

Rubio Gaviria, David Andrés y Jiménez Guevara, Julián Ernesto, "Constructivismo y tecnologías en educación. Entre la innovación y el aprender a aprender" Revista Historia de la Educación Latinoamericana vol.23 no.36 (2021)

\author{
David Andrés Rubio Gaviria' \\ Universidad Pedagógica Nacional, Colombia \\ https://orcid.org/0000-0002-4102-8267 \\ Julián Ernesto Jiménez Guevara² \\ Secretaría de Educación Distrital de Bogotá, Colombia \\ https://orcid.org/0000-0002-2869-0205
}

\section{Resumen}

Objetivo: del artículo ${ }^{3}$ es caracterizar las condiciones de posibilidad del discurso sobre el constructivismo en educación, que es a su vez un discurso que incluye la tecnología como uno de sus pilares.

1 Profesor asociado de la Universidad Pedagógica Nacional. Miembro del Grupo de Historia de la Práctica Pedagógica. Investigador principal del proyecto "De la crisis mundial de la educación a la crisis mundial del aprendizaje. 50 años de producción de discurso educacional de la UNESCO" (DSI-511-20). darubiogaviria@yahoo.es

2 Docente de Español y Literatura de la Secretaría de Educación Distrital de Bogotá. Magíster en Educación con énfasis en Gestión y Evaluación Educativa. Miembro del equipo de construcción de las pruebas SABER de Lenguaje del ICFES. vincentfukuda@yahoo.es

3 El artículo presenta resultados parciales del proyecto de investigación "De la crisis mundial de la educación a la crisis mundial del aprendizaje. 50 años de producción de discurso educacional de la UNESCO" (DSI511-20), financiado por el Centro de Investigaciones de la Universidad Pedagógica Nacional, bajo la Coordinación de David Rubio Gaviria, durante 2020. Del mismo modo, el artículo esboza resultados preliminares de la tesis doctoral "Análisis arqueogenalógico del constructivismo en educación", adelantada por Julián Jiménez Guevara. 
Originalidad/aporte: el trabajo problematiza el sentido de la "sociedad del conocimiento", cuestiona la relación entre las competencias en educación y la innovación, así como interroga el discurso del "aprender a aprender" como el asunto central de la educación que se asume como constructivista.

Método: Revisión documental.

Estrategias/recolección de información: Lectura temática de documentos sobre política educativa producidos por agencias internacionales.

Conclusiones: se propone que el constructivismo se popularizó porque parece recoger lo propuesto alrededor de "la sociedad del conocimiento" y el discurso sobre las "necesidades de aprendizaje" promovido por agencias internacionales. Se sugiere, de igual modo, que la innovación es una condición estructural de la educación contemporánea, lo que explica los discursos del desarrollo de habilidades y competencias, donde no se trata de aprender algo, sino de aprender a aprender.

Palabras clave: Tecnología; sociedad del conocimiento; competencias; innovación; constructivismo.

\section{Constructivism and technologies in education. Between innovation and learning to learn}

\section{Abstract}

The objective of paper is to characterize the conditions of possibility of the discourse on constructivism in education, which is in turn a discourse that includes technology as one of its pillars.

Originality / contribution: the work problematizes the meaning of the "knowledge society", questions the relationship between competences in education and innovation, as well as questions the discourse of "learning to learn" as the central issue of education that is assumed as constructivist.

\section{Method/ strategies Document review.}

Strategies: Thematic reading of documents on educational policy produced by international agencies.

To conclude: it is proposed that constructivism became popular because it seems to reflect what is proposed around "the knowledge society" and the discourse on "learning needs" promoted by international agencies. In the same way, it is suggested that innovation is a structural condition of contemporary education, which explains the discourses of the development of skills and competencies, where it is not about learning something, but about learning to learn.

Keywords: Technology; knowledge society; competences; innovation; constructivism. 


\section{Construtivismo e tecnologias na educação. Entre inovação e aprender a aprender}

\section{Resumo}

Objetivo: do artigo é caracterizar as condições de possibilidade do discurso sobre o construtivismo na educação, que por sua vez é um discurso que tem a tecnologia como um de seus pilares.

Originalidade/aporte: o trabalho problematiza o significado da "sociedade do conhecimento", questiona a relação entre competências em educação e inovação, bem como questiona o discurso do "aprender a aprender" como questão central da educação que se assume como construtivista.

Método: Revisão de documentos.

Estratégia de recoleccion de informação: Leitura temática de documentos sobre política educacional produzidos por agências internacionais.

Conclusões: propõe-se que o construtivismo se popularizou porque parece refletir o que se propõe em torno da "sociedade do conhecimento" e do discurso sobre as "necessidades de aprendizagem" promovido pelas agências internacionais. Sugere-se, da mesma forma, que a inovação é uma condição estrutural da educação contemporânea, que explica os discursos do desenvolvimento de habilidades e competências, onde não se trata de aprender algo, mas de aprender a aprender.

Palavras chave: Tecnología, sociedade do conhecimento, competências, inovação, construtivismo.

\section{Introducción}

El desarrollo tecnológico ha sido particularmente intenso en las últimas cuatro décadas, cuando salió al mercado el primer PC fabricado por IBM, con procesador de Intel y sistema operativo de Microsoft. Aunque desde la década de 1950 se había puesto en el orden del discurso sobre la educación una idea nueva sobre el funcionamiento del cerebro humano y las condiciones de su aprendizaje, con la metáfora del ordenador y el procesamiento de información ${ }^{4}$, fue hasta la década del ochenta que el uso de las tecnologías para la educación se intensificó. En 1984 se celebró la primera "Feria Británica de la Educación, la Capacitación y la Tecnología", el BETT Show, considerada "la feria comercial educativa más grande del mundo"s.

4 Juan Ignacio Pozo, Teorías cognitivas del aprendizaje (Madrid: Morata, 2006), 29-30.

5 David Buckingham, Más allá de la tecnología. Aprendizaje infantil en la era de la cultura digital (Buenos Aires: Manantial, 2007), 14. 
Corporaciones internacionales de amplio reconocimiento (Microsoft, Apple, Oracle, Dell) venden sus productos en esta y otras ferias de naturaleza similar en el mundo a un creciente mercado educativo, mientras que gobiernos y empresas invierten, año tras año, grandes sumas de dinero en la perspectiva de actualizar sus sistemas educativos, en materia de acceso tecnológico. Estas inversiones forman parte de lo gastado en el rubro I+D (investigación y desarrollo) y son variables entre los países ${ }^{6}$; no obstante, es del orden de lo deseable que los países continúen haciendo esfuerzos de "inversión en ciencia, tecnología e innovación", puesto que "es fundamental para el desarrollo económico y el progreso social"7. Sabemos bien que el progreso social y el desarrollo económico tienen bisagra en la educación, según el orden contemporáneo.

El uso de la computadora para la educación ha estado asociado no solamente a un aumento de la eficiencia y el desarrollo "de herramientas requeridas en el mundo del trabajo", sino que también se ha planteado que "la tecnología [digital] les da a los estudiantes la libertad de seguir sus propios intereses individuales y elegir sus propios senderos de aprendizaje, al tiempo que libera a los docentes de las tareas de la administración y la evaluación, y les permite relacionarse con los alumnos de una manera más natural y auténtica"'. El matrimonio educación-tecnología (digital) no solamente se localiza en el discurso más amplio de la educación para el desarrollo, sino que algo nos dice sobre los métodos de enseñanza. Al modo de un mandamiento, los estudiantes han de ser más libres, elegirán sus propios caminos para aprender, y seguirán sus intereses individuales. Los maestros, en el mismo credo, tendrán relaciones más naturales (¿horizontales?) y más auténticas (¿democráticas?) con sus alumnos. Estas formas que adquieren el alumno y el maestro tecnologizados son afines con una suerte de progresismo contemporáneo en pedagogía que agrupa unas teorías sobre el aprendizaje, unas concepciones de la enseñanza, una versión sobre la escuela, y una afinidad con la política educativa: el constructivismo.

El presente artículo no tratará de dilucidar en su obviedad la relación entre el uso de tecnologías digitales en educación y el constructivismo, como tampoco se ocupará de analizar las oportunidades o las desventajas de una educación constructivista sustentada en las tecnologías. En cambio, el texto se propone mostrar algunas líneas de fuerza que hacen posible la vinculación entre educación y tecnología, como producto de análisis de algunos enunciados que se producen desde las agencias multilaterales interesadas en el campo educativo, especialmente la UNESCO. El tema central del artículo no es, por lo tanto, el constructivismo, sino que el énfasis estará más orientado a mostrar cómo la innovación, el aprendizaje, las competencias y el conocimiento (en su cambio de estatuto hoy), son categorías imprescindibles para identificar las condiciones de posibilidad de una educación que se pretende tecnologizada y, por consiguiente, constructivista. No obstante, en la parte final del texto realizaremos una breve aproximación a los modos de apropiación del constructivismo en el discurso sobre la

6 Con datos de 2018, la inversión de Colombia en I+D fue inferior al 0,8 \%, mientras que en otros países esta cifra fue superior: Corea del Sur, 4,23 \%; Japón, 3,29 \%; Alemania, 2,79 \%; Estados Unidos, 2,79 \% (Dinero, 2018).

7 UNESCO, "Invertir en ciencia, tecnología e innovación" (Santiago: UNESCO, 2019). https://es.unesco.org/themes/invertir-ciencia-tecnologia-e-innovacion (13 de agosto, 2020).

8 Buckingham, Más allá de la tecnología, 54.

9 lbíd. 
educación, apoyados en trabajos de autores locales, a fin de mostrar los modos particulares de reconceptualización del aprendizaje y el conocimiento que allí emergen.

\section{Las competencias}

La Organización para la Cooperación y el Desarrollo Económicos (OcDE), en 2005, dio a conocer un proyecto en el que se definen y seleccionan "las competencias consideradas esenciales para la vida de las personas y el buen funcionamiento de la sociedad"10. Esta selección, que inició en 1997 con actividades marco financiadas por la OcDE como el "Proyecto de Competencias Curriculares Transversales, la Encuesta Internacional de Alfabetismo de Adultos y el proyecto de Indicadores de Capital Humano"l1 , se publicó en un documento breve bajo el título Definición y selección de competencias clave ${ }^{12}$, más tarde popularizado con el acrónimo DeSeCo. El documento DeSeCo, que es apenas un resumen publicado para facilitar el acceso a maestros y otros interesados en el campo de la educación, toma como punto de partida un informe previo que se titula Competencias clave para una vida exitosa y un buen funcionamiento en la sociedad.

En DeSeCo se define la competencia como algo que está más allá del conocimiento y de la destreza. Involucra "la habilidad de enfrentar demandas complejas, apoyándose en y movilizando recursos psicosociales (incluyendo destrezas y actitudes) en un contexto en particular"13. A juicio de la OCDE, no es posible organizar un listado que incluya todo lo que requiere un individuo para encarar la multiplicidad de situaciones a las que se ve abocado en el curso de su vida. En cambio, los académicos y expertos que colaboraron con DeSeCo parecieron encontrar un mecanismo que les permitió agrupar "un conjunto pequeño de competencias clave"14 a partir de unos atributos generales. Así, cada "competencia clave", cuando menos, contribuye a buenos resultados para los individuos y sus sociedades; ayuda a que cada individuo enfrente variadas demandas en múltiples contextos; y es relevante para especialistas y para cada individuo.

Otro rasgo de las competencias clave es que se sintonizan con los acelerados cambios que sufre un mundo cada vez más globalizado, diverso e interconectado, a la manera de un enunciado habitual en nuestra época; parece innegable que la descripción más adecuada del mundo hoy es su carácter global, diverso y de interconexión. Para un mundo que se dota de tales características, según la OCDE, los individuos requieren altos niveles de comprensión (seguramente para afrontar la globalización y la diversidad) y de

10 José J. Brunner, "Competencias para la vida: Proyecto DeSeCo" (diciembre, 2005) https://www.brunner.cl/?p=485 (10 de agosto, 2020).

11 Laura Hersh et al., Proyectos sobre Competencias en el contexto de la OCDE. Análisis de base teórica y conceptual (París: OCDE, 1999). https://www.deseco.ch/bfs/deseco/en/index/03/02.parsys.59225.downloadList.58329.DownloadFile.tmp/1999.proyectoscompetencias.pdf (15 de julio, 2020).

12 OCDE, "La definición y selección de competencias clave. Resumen ejecutivo" (París: OCDE, 2005) https://www.deseco.ch/bfs/deseco/en/index/03/02.parsys.78532.downloadList.94248.DownloadFile.tmp/2005.dscexecutivesummary.sp.pdf (15 de abril, 2019).

13 Ibíd., 3.

14 Ibíd. 
funcionalidad (para habitar en la interconectividad). En este entendido, cada individuo, no las masas poblacionales o las comunidades, sino cada uno, "necesita dominar las tecnologías cambiantes y comprender enormes cantidades de información disponible"15. En la perspectiva del grupo o la comunidad, es menester la capacidad (ila competencia?) para enfrentar desafíos colectivos tales como la necesidad de balance "entre el crecimiento económico y la sostenibilidad ambiental, y la prosperidad con la equidad social"16. En la dimensión individual, parece claro para la OCDE que es necesario comprender el mundo en el que se vive, en tanto globalizado y diverso. Cada uno debe ser funcional, a través del acceso y uso de la información que viaja en enormes cantidades, dada la multiplicidad de medios que lo interconectan. De nuevo, en lo que atañe al grupo, el asunto parece no ser del todo distinto, pues al fin y al cabo las tensiones entre las necesidades de sustentabilidad del ambiente y el crecimiento económico; entre la prosperidad de las sociedades y la necesidad de equidad, es una vez más el acceso a la información y la participación en el juego de las interconexiones, donde se ubicarían las respuestas. En este juego del lenguaje todos estamos involucrados: "joven o viejo, hombre o mujer, pobre o rico, siempre está situado sobre nudos de comunicación, por ínfimos que estos sean"17.

La importancia de DeSeCo no solamente está en su carácter de marco para las prácticas de la evaluación internacional en el siglo xxi en materia de lo que hacen los sistemas educativos del mundo, sino en que vehicula dos enunciados centrales de toda discusión en educación hoy: que el mundo cambia aceleradamente y hay que estar a tono con tales cambios, vía el acceso a la información y mediante el uso de la tecnología; y que el crecimiento económico y el sostenimiento del ambiente han de ser posibles, también, por la vía del adecuado uso de la ingente cantidad de información disponible para ello. Esto último, por supuesto, mediante la optimización y uso de los recursos que provee la tecnología.

Un mundo que está interconectado y que en tal condición se transforma de modo rápido; un mundo que por efecto de su aceleración exige equilibrios entre el ambiente y los mercados, que demanda sustentabilidad ambiental y económica, es una idea que, a modo de eslogan, podemos encontrar en proyectos educativos, como parte de folletos de instituciones que ofertan alternativas de formación, en medios de comunicación masiva; en suma, en todas partes. Sin embargo, se trata de enunciados que han circulado, de manera especial, en agencias e instituciones multilaterales que, como en el caso de OCDE, tienen intereses en la educación. Este es el caso, por ejemplo, de UnEsCo. Para esta agencia,

Preparar a los estudiantes para el trabajo, la ciudadanía y la vida en el siglo XXI constituye un enorme reto. La mundialización, las nuevas tecnologías, las migraciones, la competencia internacional, la evolución de los mercados y los desafios medioambientales y políticos transnacionales son todos ellos factores que rigen la adquisición de las competencias y los

\footnotetext{
15 Ibíd., 4.

16 Ibíd.

17 Jean F. Lyotard, La condición postmoderna (Madrid: Cátedra, 1984), 37.
} 
conocimientos que las y los estudiantes necesitan para sobrevivir y salir airosos en el siglo $X X I^{18}$

Nuestro modo de encarar la condición de un mundo que ahora es más veloz es, según este mismo orden de enunciación, a través del acceso y desarrollo de competencias. DeSeCo, en su interés por identificar competencias claves, avanzó en "tres amplias categorías"19. primero, competencias que aluden al uso de grandes "rangos de herramientas para interactuar efectivamente con el ambiente: tanto físicas como en la tecnología de la información y socioculturales como en el uso del lenguaje"; segundo, competencias orientadas a garantizar la comunicación entre individuos, esto es, para que "puedan interactuar en grupos heterogéneos"; tercero, competencias relacionadas con aquello que requieren los individuos "para tomar la responsabilidad de manejar sus propias vidas", situarse así en contextos más amplios y "actuar de manera autónoma"20.

Estos tres ámbitos de competencias tienen varios rasgos comunes. Uno de ellos se relaciona con la idea según la cual el mundo se transforma velozmente y los individuos han de adaptarse, entonces, no al mundo, sino a la condición de cambio. En segundo lugar, el cambio del mundo está signado, a su vez, por el cambio tecnológico. En tercer lugar, el mundo cambiante transforma las relaciones entre los individuos, dado que fragmenta lo que antes parecía sólido y estamos compelidos a interactuar, cada vez más, con lo diferente. En cuarto lugar, y dadas estas cambiantes formas de la interacción, nuestra actuación en el mundo está "sujeta a unas influencias (como la competencia económica) y a consecuencias (como la contaminación)"21, que no distinguen territorios locales, banderas nacionales, o alianzas continentales. Estas características comunes de las competencias clave de la OCDE completan el bosquejo de los enunciados generales descritos atrás y parecen encuadrar, sin mayor necesidad de análisis, con las orientaciones de política educativa transnacional (sea la propia OCDE un ejemplo de ello), y también con las aspiraciones microcurriculares más remotas.

UnESCO, desde luego, hizo público su propio conjunto de competencias, en el que además se explicitan las necesidades del mundo laboral de nuestro siglo. Estos conjuntos de competencias, organizados también en tres, se orientan a los ámbitos personal, esto es, "la capacidad de iniciativa, la resiliencia, la responsabilidad, la asunción de riesgos y la creatividad"; social, como "el trabajo en equipo, el trabajo en red, la empatía y la compasión"; y las competencias de aprendizaje, como "la gestión, la organización, las capacidades metacognitivas y la habilidad de convertir las dificultades en oportunidades"22.

Una alianza constituida en 2012 por la Universidad de Melbourne, Cisco, Intel y Microsoft, establecida en Australia, Costa Rica, los Estados Unidos, Países Bajos, Finlandia

18 Cynthia Scott, "El futuro del aprendizaje 2. ¿Qué tipo de aprendizaje se necesita para el siglo XXI? Investigación y prospectiva en educación". Documentos de trabajo ERF, n. ${ }^{\circ} 14$ (París: UNESCO, 2015) https://unesdoc.unesco.org/ ark:/48223/pf0000242996_spa (5 de julio, 2020).

19 OCDE, "La definición y selección de competencias clave", 5.

20 Ibíd.

21 ibíd., 6.

22 Scott, "El futuro del aprendizaje 2". 
y Singapur, pero con participación de instituciones e investigadores de todo el mundo ${ }^{23}$, señaló en su proyecto sobre "Evaluación y Enseñanza de las Competencias del Siglo XXI (ATC21S)"24 cuatro categorías generales: "maneras de pensar, maneras de trabajar, herramientas para trabajar y competencias para vivir en el mundo"25. De otro lado, el Apollo Education Group, una empresa que se encarga de la administración y operación de varias universidades de Estados Unidos, México, Reino Unido y Chile, con sede principal en Chicago, presentó también en 2012 su propio listado de competencias para el siglo xXI. El listado es más amplio que los ofrecidos por UnESCO, OCDE o ATC21S, aunque con idéntica orientación: "pensamiento crítico, comunicación, liderazgo, colaboración, adaptabilidad, productividad y rendición de cuentas, innovación, ciudadanía mundial, emprendimiento, y capacidad para acceder a la información, analizarla y sintetizarla"26.

Estos conjuntos de competencias, más cercanos a un lenguaje del aprendizaje que a uno de la educación ${ }^{27}$, se orientan a una inquietud por el futuro, en su condición de incierto por el cambio acelerado, en lo que dan a llamar "la visión general del aprendizaje del siglo xxi"28. En esta visión, "la personalización, la colaboración, la comunicación, el aprendizaje informal, la productividad y la creación de contenido"29 son atributos de las competencias imprescindibles hoy. De este modo, a raíz de la "creciente preocupación sobre las posibles crisis económicas y mundiales futuras, se plantea la cuestión de saber si las y los estudiantes de hoy en día cuentan con la combinación de pensamiento crítico, creatividad y habilidades de colaboración y de comunicación que resulta necesaria para lidiar con las nuevas situaciones inesperadas que afrontarán"30. En el caso de los educadores, otros análisis plantean que la cuestión es "cómo preparar a sus estudiantes para integrarse a un mundo laboral que aún no ha sido concebido. Según el Foro Económico Mundial (2016), las ocupaciones más demandadas actualmente en las industrias no existían hace 10 años"31.

La inquietud por el futuro y el uso de tecnologías digitales son frecuentes en los documentos que producen las agencias multilaterales sobre las competencias y habilidades necesarias para el siglo XXI. OCDE, Banco Mundial, o UnESCO, no conciben nuestro presente sin ambas cuestiones. Las incertezas sobre un mundo de cambios (la inquietud por el futuro), se buscan satisfacer con una virtualización perenne de las acciones (el uso

23 lbíd.

24 Ibíd., 4.

25 Ibíd.

26 Mary Barry, What skills will you need to succeed in the future? (2012) [Traducción propia]. https://www.phoenix.edu/ forward/careers/2012/09/what-skills-will-you-need-to-succeedin-the-future.html (27 de junio, 2020).

27 Gert J. J. Biesta, El bello riesgo de educar. Cada acto educativo es singular y abierto a lo imprevisto (Barcelona: Ediciones SM, 2017), 15-16.

28 Scott, "El futuro del aprendizaje 2".

29 lbíd.

30 Ibíd., 1.

31 Jorge Sanabria y Margarida Romero, "Competencias del siglo XXI en proyectos co-tecnocreativos". Revista mexicana de bachillerato a distancia vol. 10, n. ${ }^{\circ} 19$ (2018): 17. 
de las tecnologías digitales). No obstante, no se trata tanto de educar para un mundo futuro que ahora nos es desconocido, sino de educar para el cambio. Los cambios son acelerados, como se indica también en todos los documentos sobre competencias que hasta acá se han citado, y los criterios de la educación no estarían más sustentados en la bienvenida de las generaciones nuevas al mundo, en el sentido de Arendt ${ }^{32}$, sino en una suerte de recibimiento a lo que no es fijo, estático, sino imprevisible. Damos la bienvenida a lo que no sabemos y la educación ingresa en una contradicción. Educar a las nuevas generaciones para los cambios, equivale a educarlas en nada concreto, sino más bien en competencias.

Uno de los rasgos distintivos de las competencias es su carácter potencial; tratarse de algo que todavía no es, pero que podrá ser. Las competencias fungen como una suerte de promesa y, por eso, sus valores más destacables son la creatividad y la innovación, como dice el gurú de la educación para el cambio, Ken Robinson, al afirmar ${ }^{33}$ que nuestro futuro está condicionado por nuestra habilidad de "reestructurar nuestra manera de entender la capacidad humana y dar un lugar destacado a la creatividad y la innovación en nuestros sistemas educativos" ${ }^{\text {"34 }}$. Esta reestructuración del entendimiento a la que alude Robinson, distante en sustancia del entendimiento como un asunto de la conducción o del gobierno de los niños, como pensara la educación moderna ${ }^{35}$, alude a otro atributo imprescindible de las competencias: la flexibilidad. Innovación y creatividad solo tienen lugar en mentes flexibles, cuyos procesos cognitivos sean suficientemente adaptables a las condiciones cambiantes a las que nos sometemos.

Innovación, creatividad y flexibilidad son atributos comunes en la abundante literatura sobre las competencias para el siglo $\mathrm{xx}^{36}$. El informe La educación encierra un tesoro, financiado por UNESCO de cara a las necesidades de la educación del siglo XXI, es la referencia común en dicha literatura. Para Delors y sus colegas, la educación del siglo xxi debería atender a un reto doble e incluso contradictorio: por un lado, y como efecto de la ilimitada circulación de información por la vía de las tecnologías, la educación habría de transmitir eficaz y rápidamente "un volumen cada vez mayor de conocimientos teóricos y técnicos evolutivos, adaptados a la civilización cognitiva, porque son las

32 Hannah Arendt, Entre el pasado y el futuro. Ocho ejercicios sobre la reflexión política (Barcelona: Ariel, 2016).

33 La conferencia "¿Las escuelas matan la creatividad?" que hizo famoso a este "gurú" de la creatividad y la educación, un oficio que es solo posible en las condiciones contemporáneas, fue pronunciada en 2006 y cuenta hoy con más de 66 millones de reproducciones en un canal de internet. Es particularmente interesante de la conferencia que Robinson, por la vía de algunas anécdotas personales, trata de mostrar que la creatividad es una condición natural de los seres humanos, que es coartada por la escuela. No obstante, él mismo es un producto de la educación escolar, así como los personajes de sus ejemplos, quienes desplegaron todo su potencial creativo gracias a su participación en formas institucionalizadas de educación. Este es el caso de la maestra de danza de reconocimiento mundial que logró su gran nivel gracias a las clases que recibió en una prestigiosa academia de danza en Inglaterra, y que es amiga personal del conferencista.

34 Ken Robinson, "Do Schools Kill Creativity?", conferencia en TED Talks, emitida en 2006 (20:04), https://www.ted. com/talks/sir_ken_robinson_do_schools_kill_creativity?language=es (10 de agosto, 2020).

35 Carlos Noguera, "Notas sobre el fin de la educación”, en Genealogías de la pedagogía, comp. Carlos Noguera y David Rubio (Bogotá: Universidad Pedagógica Nacional, 2019), 175-196.

36 Scott, "El futuro del aprendizaje". 
bases de las competencias del futuro"37. Por otro lado, esta misma educación tendría que encargarse de evitar que las nuevas generaciones se extraviaran en el incesante mar de interconexiones. La educación, dice Delors, "se ve obligada a proporcionar las cartas náuticas de un mundo complejo y en perpetua agitación, y al mismo tiempo la brújula para navegar por él"38.

En la perspectiva del Informe, el saber acumulado en la escuela sería insuficiente para navegar el mundo, razón por la cual se hacía necesario que las nuevas generaciones contaran con las competencias básicas para aprovechar todas las oportunidades que el paisaje marítimo brindara para continuar en la ruta. Sin embargo, como se ha analizado hasta acá, no es muy claro el destino final ni la orientación de la brújula. Estas competencias, tímidamente señaladas por Delors, pero desarrolladas a granel en las dos décadas siguientes a su Informe, habrían de sustentarse en "cuatro aprendizajes fundamentales, que en el transcurso de la vida serán para cada persona, en cierto sentido, los pilares del conocimiento"39.

Aprender a conocer (adquisición de instrumentos para la comprensión); aprender a hacer (para influir en el entorno); aprender a vivir juntos (para cooperar con los demás); y aprender a ser (un proceso de síntesis de los primeros tres), son los cuatro aprendizajes formulados por la Comisión y, como se aprecia en nuestros análisis, entronizan en su aspiración con las competencias para afrontar el siglo XXI. En perspectiva de $\mathrm{OCDE}^{40}$, los grupos de competencias clave se orientan al uso interactivo de herramientas, la necesidad de interaccionar en y con grupos heterogéneos, y actuar autónomamente. Estos tres grupos de competencias clave, según analizan Angulo y Redon ${ }^{41}$, parecen dialogar con lo formulado por Delors y sus colegas, excepto por un estratégico olvido: aprender a conocer.

En el Informe de Delors, el tesoro que encierra la educación estaría escondido en el interior de cada individuo, y la labor de la educación sería desenterrarlo mediante los caminos de los aprendizajes descritos, así como mediante la promoción y el incremento de "las posibilidades creativas" 42 de cada uno. No obstante, parece claro para Delors que, si bien aprender a ser sería el corolario para el encuentro del tesoro, no mucho podría hacerse sin instrumentos para comprender el proceso, esto es, sin aprender a conocer. Para Morin, en otro texto emblemático preparado para UnESCO, es alarmante que la educación "permanezca ciega ante lo que es el conocimiento humano, sus disposicio-

37 Jaques Delors et al., La educación encierra un tesoro. Informe a la Unesco de la Comisión Internacional sobre la Educación para el siglo XXI (París: Ediciones UNESCO, 1996) https://unesdoc.unesco.org/ark:/48223/pf0000109590_ spa (15 de abril, 2020).

38 Ibíd., 95 .

39 lbíd.

40 OCDE, "La definición y selección de competencias clave".

41 Félix Angulo y Silvia Redon, "Competencias y contenidos: cada uno en su sitio en la formación docente". Estudios pedagógicos vol. 37, n.ㄱㄹ (2011): 282.

42 Delors et al., "La educación encierra un tesoro", 96. 
nes, sus imperfecciones [...] y no se preocupe en absoluto por hacer conocer lo que es conocer" 43 . El "conocimiento del conocimiento" formaría parte de uno de Los siete saberes necesarios para la educación del siglo XXI, y su centralidad radica en que no es una sustancia que se adquiere, unos sistemas conceptuales a los que se accede para entender asuntos del mundo, sino en su carácter siempre abierto: la educación, dice Morin, ha de "despejar los grandes interrogantes sobre nuestra posibilidad de conocer" ${ }^{44}$. En otras palabras, se trata de un conocimiento cuya naturaleza reposa en ser abierto, esto es, no ser nada concreto, sino más bien una promesa para interrogar, renovadamente, a un mundo igualmente abierto, por no decir incierto.

Pero introduzcamos una pausa. ¿Qué es lo que dice Morin sobre el conocimiento? ¿Qué sería un conocimiento del conocimiento, si aquel es insustancial, no anclado en conceptos o teorías? ¿Si el mundo, objeto del conocer, es igualmente insustancial porque no está en el ahora sino en un más allá al que se ha dado a llamar futuro e incertidumbre (el quinto saber necesario de Morin versa precisamente sobre el cómo enfrentar la incertidumbre)? Aunque la retórica sobre el saber de Morin, desde luego, merecería análisis independientes, dejemos a juicio del lector las siguientes afirmaciones que, en su opacidad, son destacables porque están en la dirección de hacer del conocimiento un asunto, cuando menos, difuso:

\begin{abstract}
El conocimiento de los problemas claves del mundo, de las informaciones claves concernientes al mundo, por aleatorio y difícil que sea, debe ser tratado so pena de imperfección cognitiva, más aún cuando el contexto actual de cualquier conocimiento político, económico, antropológico, ecológico... es el mundo mismo. La era planetaria necesita situar todo en el contexto y en la complejidad planetaria. El conocimiento del mundo, en tanto que mundo, se vuelve una necesidad intelectual y vital al mismo tiempo. Es el problema universal para todo ciudadano del nuevo milenio: ¿cómo lograr el acceso a la información sobre el mundo y cómo lograr la posibilidad de articularla y organizarla? ¿Cómo percibir y concebir el contexto, lo Global (la relación todo/partes), lo Multidimensional, lo Complejo? Para articular y organizar los conocimientos y así reconocer y conocer los problemas del mundo, es necesaria una reforma de pensamiento. Ahora bien, esta reforma es paradigmática y no programática: es la pregunta fundamental para la educación ya que tiene que ver con nuestra aptitud para organizar el conocimiento. ${ }^{45}$
\end{abstract}

Entre el Informe elaborado por Delors y sus colegas, los siete saberes necesarios de Morin, y las competencias clave de OCDE, hay una ruptura fundamental. El aprender a conocer o el conocimiento del conocimiento, se subsumen en el "uso interactivo de herramientas"46. Este uso emerge como una competencia que, de acuerdo con los análisis de Angulo y Redon, parece agrupar los pilares del aprender a conocer y aprender a hacer, desde el supuesto según el cual "conocer, es decir, desarrollar la razón y adquirir conocimientos culturales para comprender el mundo es lo mismo que usar herramientas

\footnotetext{
43 Edgar Morin, Los siete saberes necesarios para la educación del futuro (París: Ediciones UNESC0, 1999) https://www. uv.mx/dgdaie/files/2012/11/CPP-DC-Morin-Los-siete-saberes-necesarios.pdf (8 de mayo, 2020).

44 Ibíd., 12.

45 Ibíd., 15

46 OCDE. "La definición y selección de competencias clave", 5.
} 
interactivamente" ${ }^{147}$. Hacer cosas con herramientas digitales (navegar la internet, establecer comunicación con desconocidos en redes sociales, producir video... ), se asimila a conocer el mundo de modo interactivo.

Este asunto, leído en clave del trabajo de Michael Young, es reflejo de un proceso que luego derivará en importantes reformas educativas que instrumentalizan el currículo para hacer énfasis "en la experiencia [digital] que los estudiantes llevan a la escuela", esto es, convertirlo "en instrumento para motivar a los estudiantes a aprender"*8. De lo que habla Young es de una práctica que se hizo corriente en reformas curriculares en el Reino Unido después de 2008, y que se generalizaran en Colombia hacia 2016 con los Derechos Básicos del Aprendizaje. Estas reformas, en el mundo, tendieron a privilegiar los intereses y las experiencias particulares de los estudiantes, so pretexto de favorecer el desarrollo de las competencias fundamentales del siglo xxi de las que hemos hablado (o los saberes necesarios), aunque también como parte de una estrategia para mantener motivadas a las nuevas generaciones para que no abandonasen una escuela decadente, desacreditada, "asesina de la creatividad", como apuntó el famoso Ken Robinson en 2006.

En el aprender a conocer sugerido por Delors en 1996, todavía se percibía, de algún modo, una cierta relevancia al conocimiento en el proceso educativo como un medio de orientación en el mundo ${ }^{49}$, como el puerto seguro desde el que se iniciaba la navegación que metaforiza Delors. Con los saberes necesarios de Morin, y con las competencias clave de la OCDE, aunque no exclusivamente a causa de DeSeCo o de la misma organización (mal haríamos en afirmar que este giro es de responsabilidad de un documento o de una institución en particular), nos hallamos frente a un acontecimiento central: la consolidación de una sociedad del conocimiento, cuya ironía más evidente es que el conocimiento es apenas un invitado eventual en la escuela. Sobre las condiciones de posibilidad de esta sociedad del conocimiento, nos referiremos en el siguiente segmento del artículo.

El paso del aprender a conocer de Delors, hacia la competencia clave "uso interactivo de herramientas" $" 50$ no es simplemente un proceso de sustitución. En el marco amplio del cambio de siglo, un conjunto de fuerzas estaba orientando la transformación del concepto educación en relación con su sentido moderno y, en consecuencia, como una práctica próxima a su final" ${ }^{51}$. Además de la consolidación de la "sociedad del conocimiento"52, otra de esas fuerzas se relaciona con el proceso amplio de difusión y apropiación del constructivismo como una corriente de procedencia psicológica que rápidamente se instaló en el campo pedagógico. El constructivismo, además de situarse en el discurso

47 Angulo y Redon, "Competencias y contenidos", 290.

48 Michael Young, "El futuro de la educación en una sociedad del conocimiento: el argumento radical en defensa de un currículo centrado en materias". Pedagogía y Saberes, n. ${ }^{\circ} 45$ (2016): 81.

49 Andrea Alliaud y Estanislao Antelo, Los gajes del oficio: Enseñanza, pedagogía y formación (Buenos Aires: Aique, 2011).

50 OCDE, "La definición y selección de competencias clave", 5.

51 Noguera, "Notas sobre el fin de la educación", 175.

52 Peter Drucker, La sociedad poscapitalista (Barcelona: Apóstrofe, 1993). 
del cambio acelerado del mundo, de la incertidumbre sobre el futuro, y de la necesidad de vivir en la interconexión mediante el desarrollo de competencias, pareció validar una idea según la cual el desarrollo intelectual se sustenta en el privilegio de las experiencias particulares de niños y jóvenes, antes que en el acceso a conceptos. Sobre algunas formas de apropiación del constructivismo en el ámbito local nos referiremos en el apartado de conclusiones.

Las reformas curriculares analizadas por Young ${ }^{53}$, así como la instrumentalización del currículo que lo ha plegado a las llamadas necesidades de aprendizaje, han hecho que las escuelas se conviertan en "lugares de experiencia", en vez de ser espacios que privilegien una mirada del mundo como un "objeto de pensamiento" 54 . El conocimiento de la "sociedad del conocimiento" es más próximo a la futilidad de la experiencia y su carácter efímero, que a la robustez de los conceptos. Aunque esta cuestión pueda ser leída como un cambio en el estatuto del conocimiento, esto es, como un giro natural en sus formas de expresión y legitimación, sincrónico con la entrada de las sociedades "en la edad llamada posindustrial" y de las culturas en "la edad llamada posmoderna", como pensó Lyotard ${ }^{55}$, no es menos cierto que tal estatuto pueda ser cuando menos interrogado por la pedagogía y en clave de las actuales condiciones de la educación.

Vivimos en un mundo de cambio permanente, es un enunciado que parece proliferar con la llegada del siglo xxi. Que esta condición ha de encararse con el acceso y uso de las herramientas digitales y, en general, de las tecnologías, puede explicarse desde la idea de "sociedad del conocimiento". Según CePAL-UNESCO ${ }^{56}$, los cambios sociales en Occidente, derivados de las nuevas reglas de una economía basada más en la inversión en recursos humanos y menos en las tasas de ahorro o en la acumulación física de capital, implicaría la construcción de "sociedades del conocimiento" en las que, entre otras, "la educación debe ser continua y no centrarse exclusivamente en la escuela" En estas sociedades del conocimiento, "las personas continuarán aprendiendo más allá de la escuela, a lo largo de su vida y en su trabajo"s8. estas sociedades "deben estar a la altura del cambio tecnológico", de modo que "los nuevos requerimientos planteados a la educación demandan el uso de nuevas tecnologías"59. Veamos a continuación algunas consideraciones sobre la sociedad del conocimiento.

53 Young, "El futuro de la educación".

54 Ibíd. 83.

55 Lyotard, "La condición posmoderna".

56 CEPAL-UnESCO, Educación y conocimiento: Eje de la transformación productiva con equidad (Santiago de Chile: UNESCO, 1992) https://www.cepal.org/es/publicaciones/2130-educacion-conocimiento-eje-la-transformacion-productiva-equidad (30 de julio, 2020).

57 Ibíd., 48.

58 Ibíd.

59 lbíd. 


\section{Sociedad del conocimiento}

La sociedad del conocimiento, para este primer cuarto del siglo XXI, es una noción que hemos naturalizado porque ha impregnado de manera intensa el discurso de la educación, con especial difusión en las formulaciones de agencias como UNESCO, OCDE, o CePAL. Para esta última agencia, la sociedad del conocimiento está estrechamente ligada a una concepción de la educación como aprendizaje y del aprendizaje como acceso y uso de tecnologías. La serie educación-aprendizaje-tecnología, en el contexto amplio del desarrollo económico, es perceptible en toda la producción discursiva sobre la sociedad del conocimiento. Veamos:

La expansión de la economía a la sociedad de conocimiento descansa en la multiplicación de las comunidades intensivas en conocimientos [...] estas comunidades, que se caracterizan por grandes capacidades de producción y reproducción del saber, un espacio público o semipúblico de intercambio y de aprendizaje y la utilización intensiva de las tecnologías de la información, son comunidades esencialmente relacionadas con profesiones o con proyectos científicos, técnicos y económicos. Cuando sean cada vez más numerosas las comunidades de ciudadanos, usuarios y profanos, unidos por su interés común en tal o cual tema, que presenten esas mismas características, la sociedad del conocimiento emprenderá el vuelo. ${ }^{60}$

La serie educación-aprendizaje-tecnología, en su articulación con el desarrollo económico, por supuesto, no es una invención del discurso de las agencias multilaterales aparecidas después de la Segunda Guerra Mundial. Es desde el siglo xvIII, con la Revolución Industrial y el subsecuente giro que sufrió el conocimiento en Occidente, según ha analizado Druker ${ }^{61}$, que es posible apuntalar unas primeras formas de esta serie. Más allá de una precaución de método que no podríamos pasar por alto ${ }^{62}$, es aceptable el análisis del austríaco, para quien el conocimiento desde el siglo Iv a. C. y hasta mediado el siglo xvIII, en Occidente, ha transitado entre dos vertientes: una que sugiere "que la única función del conocimiento es el autoconocimiento, esto es el desarrollo intelectual, moral y espiritual de la persona [y otra que señala] que el propósito del conocimiento es hacer que quien lo tiene sea eficaz al permitirle saber qué decir y cómo decirlo"63. Estas dos vertientes, la primera platónica y la segunda atribuida a Protágoras, tendrían su correlato en Oriente; para los taoístas, el conocimiento "era la vía hacia la ilustración y la sabidu-

60 Paul A. David y Dominique Foray, "Una introducción a la economía y a la sociedad del saber", Revista internacional de ciencias sociales, n. ${ }^{\circ} 171$ (2002) https://es. slideshare.net/albiaam/la-sociedad-delconocimiento3-35134690.

61 Druker, "La sociedad poscapitalista".

62 Educación-aprendizaje-tecnología en el marco del desarrollo económico, según hemos señalado hasta acá, es apenas una propuesta esquemática para ilustrar, de manera breve, que nos interesa destacar una relación que está marcada en la "sociedad del conocimiento", pero que bajo circunstancia alguna es producto o efecto de análisis genealógicos que nos muestren unas procedencias semejantes en estos tres conceptos o conjuntos de prácticas. Otros trabajos han mostrado, por ejemplo, que la educación moderna acusa una genealogía que es próxima a las formas de gubernamentalización del Estado (Noguera, 2012), y que el aprendizaje, por otro lado, es un concepto con procedencia en la economía, la biología y la fisiología del siglo XIX, principalmente (Rubio, 2019).

63 Druker, "La sociedad poscapitalista", 28. 
ría"64, en tanto para los confucianos, se trataba más bien del qué decir y cómo decirlo, en la mira del progreso y éxito terrenales. En Occidente, la vía de Protágoras derivaría después en el trivium, la aspiración de las incipientes prácticas educativas medievales que agruparon lógica, gramática y retórica, y que más adelante serían reconocidas como "educación humanista"65.

La techne del mundo helénico, tanto para Platón como para Protágoras, estaba reservada para lo otro del conocimiento, aquello relativo al hacer. El conocimiento, bien como un asunto asociado al desarrollo intelectual y el cultivo interior, bien como un acervo para la oratoria pública, distaba de lo útil. La utilidad, señala Druker, "no era conocimiento, era arte" $^{\text {"66 }}$ y el vocablo asignado para ello, techne, abarcaba las habilidades profesionales que "en conjunto se consideraban transmisibles" ${ }^{6}$. Una techne era adquirida por la vía de la experiencia y, aunque respetable por su valor para la areté y por lo tanto para las prácticas de la paideia, no era equiparable al conocimiento en su sentido platónico o protagórico.

El contexto de la Revolución Industrial entre los siglos xVIII y xIx, sin embargo, dio lugar a la invención de la tecnología ${ }^{68}$, un vocablo constituido por techne, un arte manual distante del conocimiento, y logos, afín a la retórica en su sentido de "las fuerzas que mantienen en cohesión la comunidad humana"69, esto es, el conocimiento, tanto en su dimensión de desarrollo intelectual y moral, como en la perspectiva del buen y adecuado decir o, como dice Druker, "un conocimiento organizado, sistemático y con un fin determinado"70. Techne y logos, darían lugar a la tecnología como vocablo que, desde el punto de vista de las prácticas, era representativo de una importante proliferación en Francia, Inglaterra y Alemania, inicialmente, de escuelas para la formación en ámbitos como la agricultura, la minería y la ingeniería, al tiempo que se intensificó un uso técnico de los conocimientos, aunque esto último haya tenido mayor importancia solo hasta finales del siglo xIx. En el ámbito de la divulgación, fue la Encyclopedié de Diderot y d’Alembert, a mediados del siglo xviII, el "gran documento" que dio cuenta "de este dramático cambio de rumbo desde el arte a la tecnología [...] obra que intentó reunir de forma sistemática y organizada el saber de todas las artes, de tal manera que el no iniciado aprendiera a ser un tecnólogo"71.

Es así como podríamos presentar de modo general el alcance de la Revolución Industrial: como la "transformación mediante la tecnología de la sociedad y la civilización

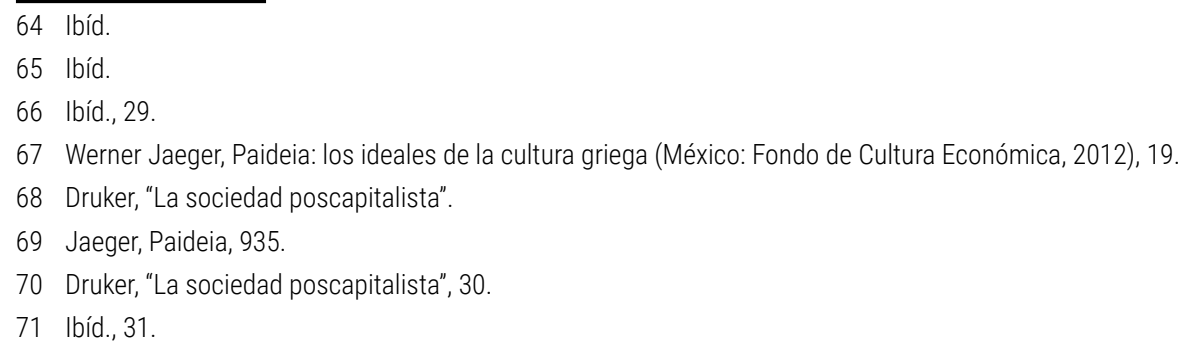


en el mundo entero"72. Pero el alcance de esta transformación del mundo, a través de la tecnología, pasaría por al menos dos nuevas etapas: la llamada "revolución de la productividad" promovida por las ideas de Taylor en los albores del siglo xx, cuyo eje revolucionario ha sido descrito como la aplicación del conocimiento al trabajo en las fábricas ${ }^{73}$, y que representó, en el periodo entre la primera y la segunda guerras mundiales, un importante aumento en la productividad en los países desarrollados, así como en el ingreso medio de los obreros en estos países, a pesar incluso de los negativos efectos de las crisis de 1929 y las propias guerras ${ }^{74}$.

La otra etapa que dará condiciones de posibilidad a lo que Druker denominó como la "sociedad postcapitalista" o "del conocimiento"75, será identificada como la "revolución de la gestión", en un giro que también puede ser leído en clave de la emergencia de "la sociedad de control" sobre la que alertara Deleuze ${ }^{76}$, y que se caracteriza, entre otras cuestiones, por un abandono de las formas de producción fabril (la forma-fábrica), hacia otras más próximas al novedoso ámbito de la gestión, en el contexto de la forma-empresa. El proletario que había aparecido con la Revolución Industrial sería reemplazado en las sociedades de control por el empresario. Es claro, como ya lo había advertido el economista neoliberal J. Schumpeter varias décadas atrás, que este empresario, forma subjetiva característica de estas nuevas sociedades, no es el capitán de empresa (el capitalista que describiera el marxismo), sino que es un hombre ordinario, capaz de emprender "combinaciones de materiales y fuerzas que se hallan a [su] alcance" 77 , y tal proceso combinatorio, de hacerse mediante métodos distintos, puede a su vez generar la producción de las mismas cosas o de cosas distintas. A este proceso de combinación alternativo, Schumpeter lo reconocerá como innovación, signo característico del burgués del siglo xx, como Sombart ${ }^{78}$ le llamó a este sujeto en el mismo periodo.

\section{Innovación}

La sociedad del conocimiento, descrita como la expansión de prácticas asociadas con la gestión en las empresas, supuso, además de la proliferación de un discurso sobre la educación permanente, unas nuevas reglas para el conocimiento, tanto en su relación

72 Ibíd., 32.

73 Anita Weiss, "¿Vigencia del taylorismo? De los enunciados a la realidad", Innovar, n. ${ }^{11}$ (1998); Hugo Garde y Cristina Etcheverry, "El taylorismo en la realidad empresarial", Enfoques: Contabilidad y Administración, n. 9 (2007).

74 Eric Hobsbawm, Historia del siglo XX (Buenos Aires: Crítica, 1998).

75 Druker, "La sociedad poscapitalista".

76 Gilles Deleuze, "Post-scriptum sobre las sociedades de control", Polis n. ${ }^{0} 13$ (2006) https://journals.openedition.org/ polis/5509 (2 de mayo, 2019).

77 Joseph Schumpeter, Teoría del desenvolvimiento económico. Una investigación sobre ganancias, capital, crédito, interés y ciclo económico (México: Fondo de Cultura Económica, 1976), 76.

78 Werner Sombart, El burgués: Contribución a la historia espiritual del hombre económico moderno (Madrid: Alianza Editorial, 1972). 
con la tecnología, como en la perspectiva del propio concepto de educación. No se trataba más, como en el sentido de Taylor, de un incremento en la productividad del obrero "como resultado de la aplicación del conocimiento al trabajo"79 sino de unas nuevas formas de la producción, consecuencia de "la aplicación del conocimiento al conocimiento" 80 . Este nuevo rol del conocimiento se expresa en los cambios sufridos por las máquinas, dado su lugar en las distintas formas de la producción. Las máquinas, como dice Deleuze, serían objetos de visibilidad de unas prácticas, "lugares de luz"81 que dejarían ver "las formaciones sociales que las han originado y que las utilizan" De este modo, mientras las sociedades del mercantilismo y la fisiocracia anteriores a la Revolución Industrial operaban con "máquinas simples, palancas, poleas, relojes; las sociedades disciplinarias [...] se equiparon con máquinas energéticas" 83 . Por su parte, las sociedades de control se caracterizan por "máquinas de un tercer tipo, máquinas informáticas y ordenadores" ${ }^{\text {", }}$, lo que no solamente constituye una mutación tecnológica sino, como hemos señalado, una profunda transformación en las formas del capitalismo, que coincide con los análisis arrojados por Druker ${ }^{85}$.

¿Qué es lo que hacen visible las máquinas informáticas y los ordenadores de la sociedad de control descrita por Deleuze? ¿Qué es lo que nos hacen ver sobre la educación?, ¿y sobre el conocimiento? La década de 1960 fue un periodo en el que tuvo lugar lo que Hobsbawm ${ }^{86}$ llamó "la revolución cultural", esto es, un momento en el cual los padres de las nuevas generaciones en Norteamérica y otras latitudes desarrolladas gozaban de pleno empleo, efecto del giro productivo que describimos más atrás, y condición que favoreció unos nuevos usos del tiempo libre para quienes no necesariamente se veían compelidos a formar parte, de modo temprano, del mundo del trabajo. Esto permitió la emergencia de una cultura juvenil, que no sería otra cosa que la expansión de las prácticas de una cultura popular que hasta entonces era marginal y que, a su vez, modificó las relaciones de familia, las ideas sobre la infancia y, de manera especial, de la propia juventud. Lo juvenil "pasó a verse no como una fase preparatoria para la vida adulta, sino, en cierto sentido, como la fase culminante del pleno desarrollo humano"87. Se trató del giro antropológico que Mead describió como el paso de las culturas posfigurativas a las prefigurativas, "en las que los pares reemplazan [... a a los padres como modelos significativos de conducta" y aquello es leído como un signo de "evolución" cultural ${ }^{88}$.

\footnotetext{
79 Druker, "La sociedad poscapitalista”, 39.

80 Ibíd.

81 Gilles Deleuze, El saber. Curso sobre Foucault (Buenos Aires: Cactus, 2013), 26.

82 Deleuze, "Sobre las sociedades de control", 3.

83 Ibíd.

84 Ibíd.

85 Druker, "La sociedad poscapitalista".

86 Hobsbawm, "Historia del siglo Xx".

87 Ibíd., 327.

88 Margaret Mead, Cultura y compromiso. Estudios sobre la ruptura generacional (Barcelona: Gedisa, 2006), 95
} 
La revolución cultural implicó una inversión en el papel de las generaciones, y lo que "los hijos podían aprender de sus padres resultaba menos evidente que lo que los

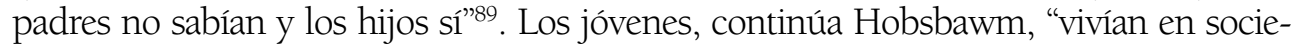
dades divorciadas de su pasado" 90 y este divorcio ocasionó una minuciosa distribución de los bienes. Las sociedades anteriores a la revolución se quedaron con sus formas del conocimiento taylorista que durante varios años (casi un siglo) sumaron de manera importante para incrementar la productividad de los obreros. Por su parte, las nuevas generaciones, intervinientes en la contracara del divorcio, se quedaron con la promesa de unas nuevas formas del conocer. No se trataba ya de un asunto relativo a la acumulación de informaciones con fines adaptativos al ambiente, como había enseñado la psicología experimental de las primeras décadas del siglo $\mathrm{xx}$, sino de la idea del procesamiento de información. El advenimiento de unas primeras formas del ordenador entre las décadas del cuarenta y el cincuenta, mostró a estas generaciones que no solamente somos capaces de crear máquinas con inteligencia artificial (IA), sino que nuestros propios cerebros funcionan como una máquina.

Que la emergente psicología cognitivista nos haya mostrado que somos como máquinas capaces de procesar información, nos ubicó frente a otros modos de comprensión sobre los usos sociales (aunque fundamentalmente individuales) del conocimiento. Los hijos de la revolución cultural dejarían de estar insertos en un capitalismo antes signado por la producción y compra de productos terminados, para disponerse a un mundo de servicios. Estos servicios, no obstante, estaban por venir. No se trataba de servicios previsibles, sino de efectos a necesidades nuevas. A esto se refiere todo discurso sobre la educación que a partir de 1960 ha insistido en un mundo en transformación, de cambio permanente, de la imprevisibilidad del futuro.

Los cambios del mundo en el contexto de la revolución cultural vienen acompañados de otro concepto, ya invocado en este artículo y con procedencia en el neoliberalismo económico de la Escuela Austriaca. Se trata de la innovación. El discurso sobre la educación agenciado por UNESCO se lo apropió rápidamente y, para principios de los setentas, lo definía de este modo: "innovación es la selección creadora, la organización y la utilización de recursos humanos y materiales de una nueva forma y original que conduzca a una mejor consecución de los fines y objetivos definidos" ${ }^{\text {". }}$. De igual modo, "la innovación nos lleva al reino de la tecnología social, a la búsqueda de la combinación de medios más eficaces para conseguir fines determinados"92.

Ahora bien, en un mundo signado por el cambio permanente, ¿cuáles serían tales fines? Dado el giro antropológico en las generaciones de esa última parte del siglo $\mathrm{xx}^{93}, \mathrm{y}$

89 Hobsbawm, "Historia del siglo xx", 328.

90 ibíd., 330.

91 Allen Huberman, Cómo se realizan los cambios en educación: una contribución al estudio de la innovación (París: Ediciones UNESCO, 1973), 8.

92 Ibíd.

93 Mead, "Cultura y compromiso". 
dado el resquebrajamiento múltiple en las formas sociales que caracterizó la revolución cultural, es claro que los fines estarían definidos por la incertidumbre: el capitalismo veía "erosionado su patrimonio histórico" $"$, pero las nuevas formas del mercado erigían el culto al yo como una nueva forma de tiranía; el modelo de la familia entraba en una crisis sin precedentes en trescientos años por la inapetencia de las nuevas generaciones por reproducirse y legar, pero la forma-empresa y el management imponían modos de vinculación entre sus miembros, a la manera de una nueva familia; la escuela comenzaba a ser cuestionada de modo intenso por su incapacidad para atender las demandas de las nuevas subjetividades ${ }^{95}$, pero el mundo reclamaba expansiones en la educación para que fuese ofrecida de manera permanente y a lo largo de la vida, en el contexto amplio de las ciudades y ya no solamente entre los muros de edificios escolares ${ }^{96}$; las instituciones educativas entraron en un periodo de inestabilidad poco percibido desde su expansión a causa de la consolidación de los Estados-Nación del siglo xix ${ }^{97}$, y como respuesta comenzaron a restarle peso a los contenidos, para dar paso "a los procedimientos y las capacidades" ${ }^{\prime \prime 8}$.

La incertidumbre, asunto central de los fines de la educación a partir de las décadas de 1960 y 1970, quedó tematizada en el importante informe Aprender a ser, escrito por un equipo liderado por Edgar Faure para UNESCO en 1973, con lo que llamaron los "tres fenómenos nuevos"99 que la educación de finales del siglo xx debía considerar: (a) que por primera vez "en la historia de la humanidad el desarrollo de la educación [... a a escala planetaria tiende a preceder al nivel del desarrollo económico"; (b) que por primera vez "en la historia la educación se emplea conscientemente en preparar a los hombres para tipos de sociedad que todavía no existen"; y (c) que por primera vez "en la historia diversas sociedades comienzan a rechazar un gran número de productos ofrecidos por la educación institucionalizada"100. Incertidumbre porque la educación comienza a convertirse en principio para el desarrollo económico (no como su efecto); porque no se trata más de formar a hombres que se inserten la vida social, sino de "formar niños desconocidos para un mundo desconocido"101; y porque comenzó a parecer urgente que la educación se adaptara a las necesidades sociales que eran, de hecho, cambiantes.

Antes estos fenómenos descritos por Faure y su comisión, la innovación de las prácticas educativas y de los sistemas en su conjunto pareció suponer una respuesta. Los

\footnotetext{
94 Hobsbawm, "Historia del siglo XX", 344.

95 Ivan Illich, La sociedad desescolarizada (Buenos Aires: Ediciones Godot, 2012); Everett Reimer, La escuela ha muerto. Alternativas en materia de educación (Barcelona: Barral Editores, 1973).

96 Edgar Faure et al., Aprender a ser. La educación del futuro (Madrid: Alianza Editorial/UNESCo, 1973).

97 Inés Dussel y Marcelo Caruso, La invención del aula. Una genealogía de las formas de enseñar (Buenos Aires: Santillana, 1999); Carlos Noguera, El gobierno pedagógico. Del arte de educar a las tradiciones pedagógicas (Bogotá: Siglo del Hombre, 2012).

98 Francisco Jódar, Alteraciones pedagógicas. Educación y políticas de la experiencia (Madrid: Laertes, 2007), 177.

99 Faure et al., "Aprender a ser", 61.

100 Ibíd., 62-63.

101 Ibíd.
} 
fines y los objetivos a los que alude el concepto de innovación, en el marco del discurso sobre la educación, harían también visible un tipo de subjetividad particular, signada asimismo por la incertidumbre: el innovador. Estamos allí, en las décadas finales del siglo $\mathrm{xx}$, al frente de una forma subjetiva con estas características:

[...] libertad para resolver problemas y buscar soluciones sin temor al castigo por desviarse de la verdad oficial y de los imperativos sociales; acentuada orientación práctica, búsqueda de información, conducta exploratoria, aceptación del riesgo, independencia.

[...]

[El innovador] confía en su propia evaluación de su experiencia; [...] siente con fuerza la necesidad de autonomía, éxito, [...] confianza en su propia capacidad para controlar el medio. [...] Los innovadores suelen ser jóvenes. ${ }^{102}$

Esta forma de subjetividad, descrita con las herramientas de una suerte de gramática del cambio permanente, no solamente impregnó las aspiraciones del Occidente desarrollado. En el caso del llamado por entonces Tercer Mundo, en las condiciones de sus necesidades de desarrollo, habría "un personaje central: el hombre y su comunidad; una dinámica constante: el cambio social; y una motivación implícita: la incesante [...] búsqueda de nuevas y mejores condiciones de existencia"103. Cambio social y búsqueda de mejores condiciones de existencia trazan límite al concepto de innovación, al menos en la perspectiva de UnESCO. En un estudio financiado por esta agencia y publicado en 1980, Havelock y Huberman señalan que la interacción de los grupos sociales con el medio implica cambios que se dan de modo irremediable o "natural"; tal interacción tiene una tendencia al equilibrio, siendo este "un fenómeno característico de todo sistema"104 político, económico, o educativo. Ahora bien, cuando estos cambios se dan por interacciones hombre-medio o grupo-medio más frecuentes o aceleradas, estaríamos "ante la presencia de síntomas de innovación"105. La innovación consiste en la búsqueda de mayores interacciones entre el hombre y su medio (o el grupo), a fin de conseguir cambios más rápidamente y que fuercen a nuevas formas de equilibrio, cuyo efecto obvio es una reorientación de objetivos y fines. La introducción de innovaciones en educación, así leída, quiere decir modificación de medios y de fines. A juicio de Havelock y Huberman, ante nuevas necesidades, es imperativo "introducir cambios fundamentales tanto en los medios como en los fines" ${ }^{\prime 106}$ y solo allí estaríamos ante la innovación.

Es particularmente interesante el análisis que arroja el estudio citado. Si la innovación no es reductible a una modificación de los medios para alcanzar fines, sino que de hecho

102 Huberman, "Cómo se realizan los cambios", 60-61 [cursivas del original].

103 Rubén Utria, "Factores institucionales y humanos inherentes a la estructura espacial del desarrollo latinoamericano: notas de clase", en Curso latinoamericano sobre planificación y administración regional de la educación, ed. Unesco (Buenos Aires: Ediciones UNESCO, 1974) https://unesdoc.unesco.org/ark:/48223/pf0000019795?posInSet=3\&queryld=e93a6681-9185-43c4-8dab-f8e81f858171 (2 de agosto, 2020), 51.

104 Ronald Havelock y Allen Huberman, Innovación y problemas de la educación: teoría y realidad en los países en desarrollo (París: Ediciones UNESCO, 1980) https://unesdoc.unesco.org/ark:/48223/pf0000136018 (17 de mayo, 2020), 47.

105 lbíd.

106 lbíd. 
implica cambios también en los fines, quiere decir que la idea de innovación se convierte en estructural; es en tal dirección que la antropóloga Françoise Héritier, la definió como un "fenómeno masivo que permite sustituir, en un ámbito determinado, un régimen antiguo por otro nuevo que llega a ser predominante paulatinamente"107. No se introducen innovaciones para mejorar el estado de un sistema, sino para modificar las reglas del propio sistema; en suma, se innova para mejorar las condiciones de posibilidad de nuevas innovaciones. Si revisamos esta idea en la perspectiva del discurso económico, quizás el asunto se esclarece: ¿A qué se refería Schumpeter ${ }^{108}$ cuando tematizaba la innovación como un asunto relativo a las nuevas combinaciones que un agente económico introduce a fin de conseguir resultados alternativos? Justamente a la alteración de los medios para modificar, incluso para crear, nuevos fines. No perdamos de vista que lo que estaba en juego en la teoría schumpeteriana, finalmente, era el desenvolvimiento económico, su desarrollo y crecimiento, no simplemente su conservación o sostenimiento. Ahora bien, ¿cuál es el tipo de conocimiento que requieren los individuos y los grupos para alcanzar las innovaciones? $\mathrm{O}$, lo que es lo mismo, ¿cómo es el conocimiento que se necesita para enfrentar la incertidumbre, esto es, la condición permanente de cambio en los fines?

La innovación como una condición estructural de la educación contemporánea, puede explicar la consistencia de los discursos que se orientan hacia el desarrollo de habilidades y competencias, como analizábamos en la primera parte del artículo. Esto quiere decir que la innovación es la condición de posibilidad del giro hacia las competencias: no es que estemos frente a unas nuevas formas de la subjetividad determinadas por la competencia, como es corriente en los análisis críticos disponibles sobre ello, sino que son las características del sujeto innovador las que le demandan ser competente. Así las cosas, es posible poner en duda la crítica recurrente que indica que el discurso de las competencias puso en crisis la importancia de los contenidos en la enseñanza. Es en la innovación donde habría que ubicar las condiciones de esta crisis y las nuevas formas del conocimiento.

Al retomar la definición antropológica de la innovación aportada por Héritier, se reafirma el giro cultural sufrido por Occidente en el último cuarto del siglo xx, relacionado con el cambio de roles de las generaciones y la futilidad de valores culturales como la experiencia y el saber fundamentado en ella. En cambio, la innovación nos habla de una cultura que "se construye basándose más en el modelo de la creatividad y la renovación que en el modelo de la permanencia y la reproducción"109. Efecto de esta cultura de la creatividad y la renovación es, desde luego, "una inestabilidad permanente"110 o, como hemos señalado, una condición constante de incertidumbre. La contrapartida a tal

107 Franç,oise Héritier citada en Informe mundial de la UNESCO, Hacia las sociedades del conocimiento (París: Ediciones UNESCO, 2005) https://unesdoc.unesco.org/ark:/48223/pf0000141908?posInSet=1\&queryld=1e72f3e6-6832-4381-960b-7c165f6bf2c9 (13 de mayo, 2020), 233.

108 Schumpeter, "Teoría del desenvolvimiento económico".

109 Informe mundial de la UnESCO, Hacia las sociedades del conocimiento, 62.

110 Ibíd. 
condición es la capacidad de aprendizaje y su "generalización en todos los niveles de la sociedad"111.

Esta generalización del aprendizaje en todos los niveles sociales, como respuesta a la inestabilidad (incertidumbre) que generan las innovaciones, deriva en lo que conocemos como "sociedad del aprendizaje". Desde este ángulo, la sociedad del aprendizaje es correlato, pero también contrapartida, de unas formas de producción cultural, política y económica caracterizadas por la innovación. Correlato, porque en una cultura de la innovación que interviene sobre los medios (las relaciones hombre-medio) y que modifica los fines, parece necesaria una actitud de aprendizaje permanente; contracara, porque ante los cambios generados por la innovación (dados en y hacia lo que es incierto), es el aprendizaje, como condición permanente de las sociedades, donde se hallarían ciertos equilibrios.

El modelo parece claro, al menos en la perspectiva de las agencias multilaterales: la innovación demanda aprendizaje permanente y en todas las esferas sociales, y el aprendizaje es la condición de base para toda innovación. Así como la innovación delinea un tipo particular de subjetividad (recordemos: libertad para resolver problemas, aceptación de riesgos, autonomía, confianza para controlar el medio...), el aprendizaje permanente se vuelca a ella. El innovador es un aprendiz permanente, un aprendiente.

El aprendiente no es el sujeto de la educación. Si bien sería necesario un análisis mucho más exhaustivo para probar esto, es posible, por ahora, esbozar algunos argumentos. La llamada por Druker "revolución de la gestión", que consistió en un paulatino abandono de las formas de la producción formuladas por Taylor a principios del siglo Xx, para dar paso a unos usos del conocimiento más orientados a su propia ampliación (ya no del conocimiento aplicado al trabajo), principalmente por la vía del uso de la inteligencia artificial y el procesamiento de información, está en la misma superficie de discurso de la "revolución cultural" descrita por Hobsbawm, aunque no se trate del mismo asunto, o de la misma revolución. La de la gestión, es una revolución que significó la tercera gran mutación del conocimiento, a juicio de Druker ${ }^{112}$, luego de lo acaecido con la invención de la tecnología en la Revolución Industrial, y luego de su uso en los procesos vinculados con el trabajo, en el contexto de la producción industrial (revolución de la productividad).

En la era de la gestión, cuya emergencia hemos localizado entre las décadas de 1950 y 1960, el conocimiento no solamente es el bastión del desarrollo económico (según Druker, los recursos naturales, la mano de obra y el capital pasan a un segundo plano), sino que su orientación es hacia sí mismo: se trata del momento histórico a partir del cual "el conocimiento se aplica de forma sistemática [... .] para definir qué nuevo conocimiento se necesita, si es factible y qué hay que hacer para que sea eficaz"113. El uso del conocimiento para reconocer cuál es el conocimiento más pertinente y qué nuevos

111 lbíd.

112 Druker, "La sociedad poscapitalista"

113 Ibíd., 39. 
conocimientos son necesarios para la producción de resultados anclados al desarrollo económico es, de hecho, lo que se define como "gestión". Por cierto, el ámbito de la gestión en educación apareció en la década de 1960 en los Estados Unidos, en 1970 en el Reino Unido, y en 1980 en América Latina ${ }^{114}$.

A este proceso de aplicación del conocimiento al conocimiento (¿aprender a conocer?, ¿conocimiento del conocimiento?), Druker también le llama "innovación sistemática"115 y los responsables son individuos o grupos que aprenden a aprender. Estos innovadores, aprendientes permanentes, han de desarrollar una relación con el conocimiento absolutamente nueva. Como quiera que sea, a este sujeto de la innovación y el cambio (el aprendiente), a ese "personaje central"116 igual que en las competencias clave del proyecto DeSeCo de la OCDE tres décadas después, se le demandaban unos atributos, todos signados por la incertidumbre como condición del presente-futuro, para el que no bastaban los conocimientos sólidos de la ciencia o la técnica, sino unas capacidades y habilidades (competencias) para resolver problemas, usualmente articulados con necesidades de innovación.

Un par de años antes de la publicación del texto de Druker, en 1990, apareció publicado uno de los textos más decisivos en materia de política educativa, además de emblemático para apreciar el giro sufrido por el concepto de educación, en este último tramo. Se trata de la Declaración Mundial sobre la educación para todos y Marco de acción para satisfacer las necesidades básicas de aprendizaje. Apenas el título de esta declaración merecería abundantes análisis. Sin embargo, es la tematización de la educación como un asunto relativo al aprendizaje permanente lo importante a destacar aquí. La Declaración es el resultado de una amplia convocatoria (155 países) que comenzó en 1989 y que estuvo a cargo de los jefes ejecutivos de UniceF, PNUD, UnEsco y Banco Mundial. Ni más ni menos. Dadas las difíciles condiciones educativas (y de pobreza) de un buen porcentaje de la población mundial, dados los retos de ampliación de la alfabetización (y de superación de la pobreza) de ese mismo porcentaje, y dadas las dificultades de acceso a las tecnologías de la información y la comunicación de más de la tercera parte de los adultos del planeta (y de pobreza), los Estados participantes proclamaron que "cada persona — niño, joven, o adulto— deberá estar en condiciones de aprovechar las oportunidades educativas ofrecidas para satisfacer sus necesidades básicas de aprendizaje"117. La satisfacción de estas necesidades pasaría por el acceso a unas "herramientas básicas" como la lectura, la escritura y el cálculo, así como a otras de índole más teórica

114 Juan Casassus, "Problemas de la gestión educativa en América Latina. La tensión entre los paradigmas de tipo A y de tipo B". Informe preliminar (UNESCO-OREALC, 2000) http://files.7o-semestre.webnode.mx/200000184-5e8c65f84a/problemas\%20de\%20gestion\%20educativa\%20en\%20america\%20latian.pdf (4 de noviembre, 2019).

115 Druker, "La sociedad poscapitalista", 40.

116 Utria, "Factores institucionales y humanos", 51.

117 UNESCO, Declaración mundial sobre la educación para todos y Marco de acción para satisfacer las necesidades básicas de aprendizaje (Nueva York: Ediciones UNESCO, 1990) http://www.postgradoune.edu.pe/pdf/documentos-academicos/ciencias-de-la-educacion/26.pdf (15 de abril, 2020), 7. 
y práctica (no se aclara si lectura, escritura y cálculo son distintas a la teoría y la práctica; todo indica que así es) y, finalmente, a otras del orden de las "aptitudes y los valores"118.

Esta descripción de los conocimientos ("herramientas básicas") se refrenda en el artículo 4 de la Declaración cuando se sugiere que la educación, además de "concentrar la atención en el aprendizaje", ha de traducirse "en desarrollo genuino del individuo", lo que depende de la adquisición de "conocimientos útiles, capacidad de raciocinio, aptitudes y valores" "119. Estos conocimientos, lejos de ser unas descripciones de contenidos, conceptos o procedimientos para el pensamiento, bien para el cultivo moral o intelectual, bien para el adecuado decir en público de la vieja tradición helénica, más parecían acercarse a los ámbitos de la gestión que describiera Druker: se trataba de unas "herramientas básicas" que en el curso del aprender a aprender, permitirían avanzar hacia otras herramientas que, a la postre, consiguieran "mejorar las condiciones de aprendizaje", como señala el artículo 6 de la Declaración. En suma, aprender para aprender y garantizar con ello que se siga aprendiendo. Los demás artículos de la Declaración (son diez en total), apuntan a exigir las condiciones materiales que los Estados habrían de garantizar para la satisfacción de las necesidades (de aprendizaje) descritas.

$\mathrm{Si}$, como hemos dicho, entre el informe liderado por Delors ${ }^{120}$ y las competencias clave de $\mathrm{O}_{C D E}{ }^{121}$ hay una ruptura en la idea que se despliega sobre el conocimiento y el rol que desempeña para la educación (más bien, el aprendizaje), es cierto también que ya desde Jontiem ${ }^{122}$ se declaraba una tendencia de relativización de las formas de saber escolares o, si se quiere, de un cambio de estatuto del conocimiento, como había anticipado Lyotard ${ }^{123}$ en la década anterior a dicha declaración. El conocimiento dejaría de ser el asunto clave de las prácticas de enseñanza en la escuela, y su lugar sería ocupado por necesidades de aprendizaje. A partir de Jontiem, de modo claro, el discurso sobre la educación se impregnaría de una idea del aprendizaje desprovisto de objetos de conocimiento y de conceptos. Más que el elemento de un proceso explicado en parte por la psicología, en parte por la didáctica, el aprendizaje colonizó todas las fronteras de la pedagogía y se posicionó como la máxima aspiración de la política educativa. La centralidad del aprendizaje ha venido modificando el alcance del conocimiento, y este último ha tomado más la forma de una herramienta, de una habilidad, o como segmento de una competencia útil para acceder a nuevos aprendizajes. La idea no es aprender algo sino aprender a aprender. Es tal vez a esto a lo que se refirió Delors al describir su aprender a conocer como un "tipo de aprendizaje que tiende menos a la adquisición de conocimientos clasificados y codificados, que al dominio de los instrumentos mismos del

\footnotetext{
118 Ibíd., 8.

119 Ibíd., 9-10.

120 Delors et al. "La educación encierra un tesoro".

121 OCDE, "La definición y selección de competencias clave".

122 UNESCO, "Declaración mundial sobre la educación para todos".

123 Lyotard, "La condición posmoderna".
} 
saber"124. En DeSeCo, como hemos dicho, la OCDE retomó esta idea instrumentalizada del conocimiento y la fusionó con el hacer, expresado como el uso de herramientas interactivas.

Las nuevas formas de legitimación del conocimiento que lo ubican en el orden de la habilidad y de la competencia, proceden, por un lado, de la constitución del concepto de tecnología dos siglos atrás y, por otro lado, del discurso de la innovación. La innovación tomó una primera forma en la economía de la Escuela Austriaca de las décadas de 1920 y 1940, y una apropiación en el discurso sobre la educación que se articuló de modo intenso con la búsqueda del desarrollo, también de orientación económica. La subjetividad característica de la innovación, cuyos atributos hemos descrito, ha constituido los fines de la educación declarados por las agencias multilaterales, así como ha contribuido en el cambio de estatuto del conocimiento en las prácticas de enseñanza. Correlato de esta forma subjetiva de la innovación se percibe en otra línea de fuerza que quedó esbozada en la primera parte del artículo, y que ahora nos proponemos describir de modo general: el constructivismo y su apropiación en el discurso sobre la educación en el ámbito local.

\section{Constructivismo: algunas conclusiones}

El constructivismo es, en lo fundamental, una teoría sobre el conocimiento. En primer lugar, es una teoría según la cual la mente humana funciona al modo de un filtro de las informaciones exteriores al individuo, con el fin de favorecer procesos de construcción de significado que se dan entre él y los objetos; esto es, una relación productiva (de construcción) entre el hombre y su medio. En segundo lugar, y como consecuencia de lo primero, es una teoría que pone en duda que todo cuanto conoce el individuo sea efecto de representaciones sobre el medio (en esto toma distancia de las perspectivas cognitivistas, que se mantienen en una línea representacionista); el conocimiento depende de los procesos mentales. En tercer lugar, es una teoría que a menudo se refiere al aprendizaje en su forma escolar, porque la mayoría de los constructivistas reconocen que es en esta institución donde suceden aprendizajes organizados, sistemáticos; en suma, significativos.

En su condición de teoría del conocimiento, que se refiere especialmente (no únicamente) a las formas en que sucede el proceso de construcción de significado en torno a él, el constructivismo no es una teoría o corriente pedagógica, como tampoco es un corpus unívoco en los campos de la psicología o de la filosofía. En cambio, se puede pensar en el constructivismo como un conjunto de conceptos y de procedimientos cuya articulación está en sus ideas sobre el conocimiento y que, por lo tanto, transita entre la psicología (porque el conocimiento supone cambios en la conducta), la filosofía (porque su objeto es precisamente el conocimiento), y la pedagogía (porque esta última debió asumir que todo cuanto implica cambios en la conducta que se derivan de una relación

124 Delors et al., "La educación encierra un tesoro", 96-97. 
con el conocimiento, le compete). Los cambios en la conducta, que suceden como efecto de la práctica y que se mantienen más o menos estables en el tiempo es, por su parte, la definición más genérica del aprendizaje ${ }^{125}$.

Sin embargo, son múltiples los constructivismos y el conjunto de conceptos y procedimientos al que nos hemos referido cae en una heterogeneidad que, incluso, la distancia de sus presupuestos iniciales. Este carácter múltiple del constructivismo se debe principalmente al proceso de apropiación realizado por el discurso sobre la educación $^{126}$. Las ideas no representacionistas del conocimiento que fueran características de los enfoques cognitivistas posteriores a la Segunda Guerra Mundial, y aún lejanos a las prácticas educativas, hicieron que el constructivismo fuera tomando relevancia para los maestros y para los gestores de política educativa, especialmente con la entrada en crisis de las ideas conductistas para la educación, a partir de la década de 1980.

Recordemos, además, que es justo en esta década en la que se intensifica la alianza entre el uso de tecnologías (el ordenador) en la educación, al tiempo que se iban posicionando reformas educativas en los países, sustentadas en un discurso sobre la sociedad del conocimiento y la innovación. Las ideas del constructivismo se fueron popularizando rápidamente, porque parecían zanjar aquello que con fuerza se sugería en los documentos de política que hemos analizado: que el sujeto de finales del siglo xx y principios del XXI habría de mantener relaciones más activas con su medio; que el medio (el mundo) está en cambio permanente; que el sujeto habría de adaptarse a lo acelerado y constante de los cambios de su medio (aprendizaje permanente); y que el conocimiento no podía ser más aquel conjunto de "enunciados que denotan o describen objetos [...] susceptibles de ser declarados verdaderos o falsos" 127 y que son legitimados por comunidades de expertos. Al contrario, parecía más prometedor y ajustado a las demandas del cambio de siglo, una idea de conocimiento como la prometida por el constructivismo: como un proceso de construcción de significado a través de interacciones, que no es estático, sino que cambia a lo largo de la vida; tal cambio se asocia con la adquisición de herramientas intelectuales que cualifican la interacción.

No sería propio de nuestros análisis pretender mostrar lo adecuado o no de estas apropiaciones de las ideas constructivistas en la educación que asemejan el conocimiento más al proceso mismo del aprendizaje, que a los productos de legitimación de comunidades científicas y de expertos. Es propio, por otro lado, sugerir la hipótesis según la cual el constructivismo en educación es un saber que se fue formando en las dos últimas décadas del siglo xx y que es coherente con las condiciones que hemos descrito a lo largo del artículo. Tal vez ello explique el eclecticismo al que han sido sometidos los presupuestos constructivistas de autores como Vygotsky, Piaget, o Ausubel, quienes

125 David Rubio, "Historia del concepto aprendizaje. Aproximación arqueo-genealógica", en Genealogías de la pedagogía, comps. Carlos Noguera y David Rubio (Bogotá: Universidad Pedagógica Nacional, 2019), 199-200.

126 Juan Delval, "Hoy todos son constructivistas", Educere vol. 5, n. 15 (2001). Gerardo Hernández, Paradigmas en psicología de la educación (México, D. F.: Paidós, 1998).

127 Lyotard, "La condición posmoderna", 43-44. 
utilizaron conceptos, procedimientos y hasta preguntas distintas en su investigación; no es posible afirmar que haya una continuidad entre ellos sino, al contrario, hasta posturas contrarias ${ }^{128}$. El constructivismo, en su forma educativa, retoma ideas procedentes de los trabajos de estos autores y, además, del procesamiento de la información, central para comprender su imbricación con el discurso sobre las tecnologías en la escuela. El constructivismo en educación no es más una teoría sobre el conocimiento, sino un marco de referencia, un tipo de saber particular cuya paternidad se halla entre la psicología de la educación (un campo que probablemente emergió apenas para dar a luz al constructivismo escolar), la pedagogía, y la política educativa.

Este eclecticismo es patente cuando Pérez y Gallego afirman que, con base en los lineamientos conceptuales y metodológicos del constructivismo, cada cual debe construir su propia conceptualización, porque "nadie puede denominarse constructivista si no ha elaborado una versión idiosincrática"129. Según esto, habría tantos constructivismos como maestros, en cuyas "versiones idiosincráticas", las interacciones entre el sujeto que aprende (que conoce) y su medio serían de una cualidad y de una naturaleza igualmente diversa. Esta variedad explicaría la razón por la cual se acude a conceptos como esquema o estructura, de procedencia piagetiana, para explicar los cambios que se efectúan en la interacción señalada, hasta afirmaciones que sugieren que, en el proceso de la interacción, lo que es construido es el propio conocimiento, y no nuevas disposiciones para su adquisición.

Pero habría otras descripciones sobre el constructivismo para las que la interacción hombre-medio, aprendiente-mundo, implican lo uno y lo otro: tanto la adecuación de disposiciones para la adquisición de nuevo conocimiento, como su propia construcción. Esta segunda idea es la más ampliamente popularizada en las prácticas escolares y, con escasa crítica, supone que los niños son "constructores de conocimiento"; que el saber previo, del que hablara Piaget en su psicogénesis, equivale al conocimiento formalizado y legitimado (no a unas disposiciones, como pensara realmente el ginebrino); y que, ya en el discurso de la tecnología, los niños "traen el chip incorporado"130. Esta última expresión, convertida en uno de los descriptores más frecuentes de las nuevas generaciones, deja la sensación de que los niños saben lo que se requiere para el manejo de todo aparato tecnológico y que este conocimiento, al modo de un "chip", viene inserto en la naturaleza infantil contemporánea.

Es así como para Castaño, lo que construimos es la manera en que organizamos las interacciones con el mundo externo; lo que hacemos es seleccionar, transformar, adaptar e incorporar las significaciones del contexto a nuestras propias estructuras cognoscitivas, para lo cual debemos construir, adaptar, reconstruir y transformar dichas estructuras.

\footnotetext{
128 Delval, "Hoy todos son constructivistas".

129 Royman Pérez y Rómulo Gallego, Corrientes constructivistas. De los mapas conceptuales a la teoría de la transformación intelectual (Bogotá: Cooperativa Editorial Magisterio, 2001), 10.

130 Rocío Rueda y Antonio Quintana, Ellos vienen con el chip incorporado. Aproximación a la cultura informática escolar (Bogotá: IDEP, 2004), 140.
} 
Entonces "se da una interacción dialéctica entre los objetos que se incorporan al conocimiento y los instrumentos cognoscitivos que permiten tal incorporación"131. Hay elementos que garantizan la continuidad entre el desarrollo psicogenético y el desarrollo sociogenético y que pueden ser la base para renovar los procesos de formación:

a. El conocimiento no surge de ideas abstractas, proposicionales, se construye en contextos socioculturales y tiene connotaciones ideológicas, en las que entra en juego el poder.

b. Ubicar al sujeto humano como constructor de conocimiento, inserto en un contexto social que le genera situaciones que constituyen un sistema de significaciones y relacionar el desarrollo de sus procesos cognoscitivos con la epistemología de las ciencias.

c. Darle sentido a la experiencia en la construcción de conocimientos, desde los mismos procesos cognoscitivos.

d. La práctica vista como una serie de acciones que se constituyen en punto de partida para generar procesos de conocimiento.

e. Concepciones de mundo que no se cuestionan y que condicionan la manera de comprender los fenómenos.

f. El conocimiento no es universal, es diverso, cambia de acuerdo con el tipo de sociedad, con el tipo de cultura y con la época.

g. Un conjunto de relaciones sociales, culturales y de poder que condicionan los marcos de investigación y una manera de pensar. ${ }^{132}$

Estas ideas condensan mucho de lo analizado a lo largo del texto. Sitúan en el constructivismo, o al menos, en estas formas del constructivismo escolar, unas responsabilidades que proceden de las necesidades de innovación que aparecieron en la sociedad del conocimiento, o en el "giro de la gestión" descrito por Druker ${ }^{133}$; la operación de las respuestas para un mundo que cambia aceleradamente; el desarrollo de competencias y habilidades para una educación inquieta por el futuro; y las promesas de un mundo tecnologizado que privilegia nuevas formas del conocimiento y nuevos tipos de aprendizaje.

Estas formas de apropiación del constructivismo se articulan con los enunciados referidos en la primera parte del artículo. De este modo, parece que esperamos de las generaciones del siglo xxI que se ocupen del hacer y no del conocer; de su experiencia individual, antes que del mundo como experiencia; de transformarse, antes que de ser. Y no es para menos. A estas generaciones no les legamos un mundo, sino que las

131 Norma Castaño, "De la Epistemología constructivista piagetiana, el reconocimiento de la cultura y de la diversidad para la formación en escenarios culturalmente diversos", Revista Colombiana de Educación, n. 00 (2011): 115.

132 lbíd., 118-119.

133 Druker, "La sociedad poscapitalista". 
arrojamos a la incertidumbre. No las educamos para orientarse en lo existente, sino para que aprendan a aprender sobre aquello que todavía no es. En este último tramo, no obstante, se agudiza la cuestión: parece que comenzamos con otro giro en el que no hay incertidumbre sobre el futuro, sino sobre los futuros, en plural.

Una nueva comisión organizada por UnEsCO se encuentra, mientras escribimos este texto, preparando un informe que se publicará a finales de 2021 y que llevará por título Los futuros de la educación. Aprender a transformarse ${ }^{134}$. Una de las diferencias entre esta comisión y las anteriores (las lideradas por Delors en 1996 o por Faure en 1973), es que apenas se ocupará de acopiar y sintetizar los anhelos y las ideas de todo el mundo, que se están recogiendo en encuestas vía internet. Se trata de los futuros de la educación porque cada individuo está convidado a participar, sin importar su aproximación al campo de la educación. Esto no quiere decir necesariamente que la educación sea un terreno susceptible de opinión (asunto cierto, entre otras), sino que denota una cierta confianza en la experticia natural de cada individuo. Es como si cada ser humano en tanto tal estuviese, apenas por efecto de la experiencia de haber nacido humano, en condiciones de experticia para realizar definiciones sobre los destinos de la educación. Es una evidencia de las condiciones contemporáneas a que nos hemos referido, en las que el conocimiento, en este caso sobre la educación, puede proceder de la experiencia personal, y no necesariamente del conocimiento de la historia de la educación, de su filosofía, de las condiciones didácticas para la enseñanza y el aprendizaje, del diseño curricular, o sobre el desarrollo psicobiológico.

Mientras las agencias multilaterales siguen produciendo listados de competencias y de habilidades como las que hemos analizado acá, mientras nuevas formas del constructivismo se apropian en las prácticas escolares, y mientras más nos convencemos de imperativos como la innovación, el emprendimiento o la reinvención (muy de moda hoy), veremos que las brechas con los países desarrollados y de alto ingreso se continuarán ampliando. Esta diferencia entre los países de América Latina, África, y buena parte del continente asiático, y los países desarrollados, es similar a la que observamos entre las escuelas públicas, de bajos recursos, y las privadas de élite ${ }^{135}$ : mientras que las primeras se esfuerzan por organizar sus actividades, sus currículos, y hasta sus prácticas de evaluación, en torno de competencias y proyectos tendientes a favorecer la experiencia individual de los niños, las segundas se siguen ocupando de la enseñanza de conceptos anclados en contenidos, aún en modelos llamados tradicionales.

La sociedad del conocimiento tiene lugar en espacios de alto ingreso y de desarrollo científico de punta: en estas sociedades, propietarias de la ciencia, el conocimiento se especializa aún más y parece posible la creación de las innovaciones que la sociedad demanda. La sociedad del conocimiento no es un asunto del Tercer Mundo, como advierte

134 UNESCO, Los futuros de la educación. Aprender a transformarse (UNESCO), https://es.unesco.org/futuresofeducation/ (25 de agosto, 2020).

135 Guillermo Bustamante, "El maestro cuadrifronte". Infancias imágenes vol. 1, n. 2 (2012). 
el propio Druker ${ }^{136}$ y las formas de conocimiento científico que ella describe, tampoco. La innovación como valor, las competencias como promesa, y el aprendizaje permanente como deseo, en las condiciones locales, no son más que emulaciones, simulacros que en realidad no afectan los grandes problemas que se esperan atacar, y cuya utilidad está en continuar creando pretextos para seguir postergando nuestras responsabilidades con las nuevas generaciones.

\section{Conflicto de interés}

Los autores declaran que no tienen conflicto de interés.

\section{Financiamiento}

El artículo presenta resultados parciales del proyecto de investigación "de la crisis mundial de la educación a la crisis mundial del aprendizaje. 50 años de producción de discurso educacional de la UnESCO" (DSI-511-20), financiado por el Centro de Investigaciones (CIUP) de la Universidad Pedagógica Nacional.

\section{Referencias}

Alliaud, Andrea y Estanislao Antelo. Los gajes del oficio: Enseñanza, pedagogía y formación. Buenos Aires: Aique, 2011.

Angulo, Félix y Silvia Redon. "Competencias y contenidos: cada uno en su sitio en la formación docente". Estudios pedagógicos 37, n. 2 (2011): 281-299. https://doi.org/10.4067/S0718-07052011000200017

Arendt, Hannah. Entre el pasado y el futuro. Ocho ejercicios sobre la reflexión política. Barcelona: Ariel, 2016.

Barry, Mary. “What skills will you need to succeed in the future?". 2012. https://www.phoenix.edu/forward/ careers/2012/09/what-skills-will-you-need-to-succeedin-the-future.html (27/6/2020).

Biesta, Gert J. J. El bello riesgo de educar. Cada acto educativo es singular y abierto a lo imprevisto. Barcelona: Ediciones SM, 2017.

Brunner, José. “Competencias para la vida: Proyecto DeSeCo". 2005. https://www.brunner.cl/?p=485 $(10 / 8 / 2020)$.

Buckingham, David. Más allá de la tecnología. Aprendizaje infantil en la era de la cultura digital. Buenos Aires: Manantial, 2017.

Bustamante, Guillermo. “El maestro cuadrifronte”. Infancias imágenes 1, n. 2 (2012): 87-97.

Casassus, Juan. “Problemas de la gestión educativa en América Latina. La tensión entre los paradigmas de tipo A y de tipo B". Informe preliminar para UNESCO-OREALC, 2000. http://files.7o-semestre. webnode.mx/200000184-5e8c65f84a/problemas\%20de\%20gestion\%20educativa\%20en\%20 america\%20latian.pdf (4/11/2019).

Castaño, Norma. "De la Epistemología constructivista piagetiana, el reconocimiento de la cultura y de la diversidad para la formación en escenarios culturalmente diversos". Revista Colombiana de Educación, n. 60 (2011): 107-122.

136 Druker, "La sociedad postcapitalista". 
CEPAL-UNESCO. Educación y conocimiento: Eje de la transformación productiva con equidad. Santiago de Chile: UNESCO, 1992. https://www.cepal.org/es/publicaciones/2130-educacion-conocimiento-eje-la-transformacion-productiva-equidad (30/7/2020).

David, Paul A. y Dominique Foray, "Una introducción a la economía y a la sociedad del saber", Revista internacional de ciencias sociales, $n .{ }^{\circ} 171,2002$. https://es.slideshare.net/albiaam/ la-sociedad-delconocimiento3-35134690

Deleuze, Gilles. "Post-scriptum sobre las sociedades de control". Polis, n. 13 (2006). https://journals. openedition.org/polis/5509 (2/05/19).

Deleuze, Gilles. El saber. Curso sobre Foucault. Buenos Aires: Cactus, 2013.

Delors, Jaques et al. La educación encierra un tesoro. Informe a la Unesco de la Comisión Internacional sobre la Educación para el siglo XXI. París: Ediciones UNESCO, 1996. https://unesdoc.unesco.org/ ark:/48223/pf0000109590_spa (15/04/20).

Delval, Juan. “Hoy todos son constructivistas". Educere 5, n. ${ }^{0} 15$ (2001): 353-359.

Dinero. “Los países que más invierten en investigación e innovación" (2018). https://www.dinero.com/ edicion-impresa/mundo/articulo/paises-que-invierten-en-innovacion/254269 (15/7/2020)

Drucker, Peter. La sociedad poscapitalista. Barcelona: Apóstrofe, 1993.

Dussel, Inés y Marcelo Caruso. La invención del aula. Una genealogía de las formas de enseñar. Buenos Aires: Santillana, 1999.

Faure, Edgar, Felipe Herrera, Abdul-Razzak Kaddoura, Henri Lopes, Arthur Petrovski, Majid Rahnema y Frederick Champion. Aprender a ser. La educación del futuro. Madrid: Alianza Editorial/UNESCO, 1973.

Garde, Hugo y Cristina Etcheverry. El taylorismo en la realidad empresarial. Enfoques: Contabilidad y Administración, n. 9 (2007): 49-65. https://repositorio.uca.edu.ar/handle/123456789/2324 (10/8/2020)

Havelock, Roland y Allen Huberman. Innovación y problemas de la educación: teoría y realidad en los países en desarrollo. París: Ediciones UNESCO, 1980. https://unesdoc.unesco.org/ark:/48223/ pf0000136018 (17/5/2020).

Hernández, Gerardo. Paradigmas en psicología de la educación. México, D. F.: Paidós, 1998.

Hernández, Gerardo. "Los constructivismos y sus implicaciones para la educación". Perfiles educativos XXX, n. ${ }^{\circ} 122$ (2008): 38-77.

Hersh, Laura, Dominique Simone, Urs Moser y John Konstant. Proyectos sobre Competencias en el contexto de la OCDE. Análisis de base teórica y conceptual. París: OCDE, 1999. https://www.deseco.ch/bfs/ deseco/en/index/03/02.parsys.59225.downloadList.58329.DownloadFile.tmp/1999.proyectoscompetencias.pdf (15/7/2020).

Hobsbawm, Eric. Historia del siglo XX. Buenos Aires: Crítica, 1998.

Huberman, A. Michael. Cómo se realizan los cambios en educación: una contribución al estudio de la innovación. París: UNESCO, 1973.

Illich, Iván. La sociedad desescolarizada. Buenos Aires: Ediciones Godot, 2012.

Informe mundial de la UnESCO. Hacia las sociedades del conocimiento. París: Ediciones UNESCO, 2005. https://unesdoc.unesco.org/ark:/48223/pf0000141908?posInSet=1\&queryld=1e72f3e6-6832-4381-960b-7c165f6bf2c9 (13/05/20).

Jaeger, Werner. Paideia: los ideales de la cultura griega. México: Fondo de Cultura Económica, 2012.

Jódar, Francisco. Alteraciones pedagógicas. Educación y políticas de la experiencia. Madrid: Laertes, 2007.

Lyotard, Jean-François. La condición postmoderna. Madrid: Cátedra, 1984.

Mead, Margaret. Cultura y compromiso. Estudios sobre la ruptura generacional. Barcelona: Gedisa, 2006.

Morin, Edgar. Los siete saberes necesarios para la educación del futuro. París: UNESCO, 1999. https:// www.uv.mx/dgdaie/files/2012/11/CPP-DC-Morin-Los-siete-saberes-necesarios.pdf (8/5/2020). 
Noguera, Carlos. El gobierno pedagógico. Del arte de educar a las tradiciones pedagógicas Bogotá: Siglo del Hombre, 2012.

Noguera, Carlos. "Notas sobre el fin de la educación". En Genealogías de la pedagogía. Cátedra doctoral, compilado por Carlos Noguera y David Rubio. Bogotá: Universidad Pedagógica Nacional, 2019, 175-196.

OCDE. "La definición y selección de competencias clave. Resumen ejecutivo". París: OCDE, 2005. https:// www.deseco.ch/bfs/deseco/en/index/03/02.parsys.78532.downloadList.94248.DownloadFile. tmp/2005.dscexecutivesummary.sp.pdf (15/4/2019).

Pérez, Royman y Rómulo Gallego. Corrientes constructivistas. De los mapas conceptuales a la teoría de la transformación intelectual. Bogotá: Cooperativa Editorial Magisterio, 2001.

Pozo, Juan Ignacio. Teorías cognitivas del aprendizaje. Madrid: Morata, 2006.

Reimer, Everett. La escuela ha muerto. Alternativas en materia de educación. Barcelona: Barral Editores, 1973.

Robinson, Ken. “Do Schools Kill Creativity?", conferencia en TED Talks, 20:04, 2006, https://www.ted.com/ talks/sir_ken_robinson_do_schools_kill_creativity?language=es (10/08/20).

Rubio, David. (2019) “Historia del concepto aprendizaje. Aproximación arqueo-genealógica”. En Genealogías de la pedagogía. Cátedra doctoral, compilado por Carlos Noguera y David Rubio. Bogotá: Universidad Pedagógica Nacional, 2019, 197-228.

Rueda, Rocío y Antonio Quintana. Ellos vienen con el chip incorporado. Aproximación a la cultura informática escolar. Bogotá: IDEP, 2004.

Sanabria, Jorge y Margarida Romero. "Competencias del siglo XXI en proyectos co-tecnocreativos". Revista mexicana de bachillerato a distancia 10, n.o 19 (2018): 16-25. https://doi.org/10.22201/ cuaed.20074751e.2018.19.64889

Schumpeter, Joseph. Teoría del desenvolvimiento económico. Una investigación sobre ganancias, capital, crédito, interés y ciclo económico. México: Fondo de Cultura Económica, 1976.

Scott, Cynthia. "El futuro del aprendizaje 2. ¿Qué tipo de aprendizaje se necesita para el siglo XXI? Investigación y prospectiva en educación". Documentos de trabajo ERF, n. ${ }^{\circ} 14$. París: UNESCO, 2015. https://unesdoc.unesco.org/ark:/48223/pf0000242996_spa (5/7/2020).

Sombart, Werner. El burgués: Contribución a la historia espiritual del hombre económico moderno. Madrid: Alianza Editorial, 1972.

UNESCO. Declaración mundial sobre la educación para todos y Marco de acción para satisfacer las necesidades básicas de aprendizaje. Nueva York: Ediciones UNESCO, 1990. http://www.postgradoune. edu.pe/pdf/documentos-academicos/ciencias-de-la-educacion/26.pdf (15/4/2020).

UNESCO. "Invertir en ciencia, tecnología e innovación”. 2019. https://es.unesco.org/themes/invertir-ciencia-tecnologia-e-innovacion (13/8/2020)

UNESCO. "Los futuros de la educación. Aprender a transformarse". 2020. https://es.unesco.org/futuresofeducation/ (25/8/2020).

Utria, Rubén. “Factores institucionales y humanos inherentes a la estructura espacial del desarrollo latinoamericano: notas de clase". En Curso latinoamericano sobre planificación y administración regional de la educación. Editado por UNESCO. Buenos Aires: Ediciones UNESCO, 1974. https://unesdoc.unesco.org/ark:/48223/pf0000019795?posInSet=3\&queryld=e93a6681-9185-43c4-8dab-f8e81f858171 $(2 / 8 / 2020)$.

Weiss, Anita. “¿Vigencia del taylorismo? De los enunciados a la realidad”. Innovar, n.o 11 (1998): 12-16.

Young, Michael. "El futuro de la educación en una sociedad del conocimiento: el argumento radical en defensa de un currículo centrado en materias". Pedagogía y Saberes, n. 45 (2016): 79-88, https:// doi.org/10.17227/01212494.45pys79.88 